\title{
Experimental study and finite element analysis on shear lag effect of thin-walled curved box beam under vehicle loads
}

\author{
Hailin Lu, Heng Cai ${ }^{a}$, Zheng Tang and Zijun Nan \\ School of Resource and Civil Engineering, Wuhan Institute of Technology, 430074, Wuhan, China
}

\begin{abstract}
Shear lag effects of curved box beam under vehicle loads are investigated by using three-dimensional finite element method, where 4 parameters of vehicle loads, load size, vehicle speed, vehicle load position, load types, are considered. The change rules of stress distribution and shear lag coefficients of upper flange at mid-span are obtained when the loads move to the mid-span. The results indicate that under vehicle loads, the peak shear lag coefficients is at the junction between the flange and web, shear lag effect is prominent, shear lag effect is greatly influenced by vehicle speed and vehicle load position, while load size and load types almost don't affect shear lag coefficients but do affect the stress. The model experiment of a cantilever curved box beam is carried out to compare with finite element analysis, and the error between them is small, which testify the validity and reliability of finite element model.
\end{abstract}

\section{Introduction}

Thin-walled box beam is a common structure type in bridge construction. Because of shear lag effect [1], stress of flange is non-uniformed distributed along width, lots of researches of shear lag effect under static loads have been studied home and abroad so far [2-6], where concentrated loads and distributed loads are utilized most of the time. Unlike straight box beam, curved box beam considered curvature radius will produce strong coupled effect of bending and torsion, making it difficult to compute its deformation and internal force, meanwhile, the impact of vehicle loads and vertical seismic excitation can intensify it if under dynamic loads, therefore it is very necessary to study shear effect of curved box beam under dynamic loads. In this paper, 3D finite element analysis is employed to study the influence of four parameters on shear lag effect under vehicle loads, experiment is performed to verify the validity of the curved box beam models.

\section{Curved box beam model}

In the paper, the material properties and structural dimensions of curved box beam are shown in the literature [7], the material parameters are as following: Young's modulus $E=3000 \mathrm{MPa}$, Poisson's ratio $\mu=0.385$, mass density $\rho=1180 \mathrm{~kg} / \mathrm{m}^{3}$. Structural parameters: thickness of bottom and upper flange

\footnotetext{
${ }^{\text {a }}$ Corresponding author : 2319944517@qq.com
}

(C) The Authors, published by EDP Sciences. This is an open access article distributed under the terms of the Creative Commons Attribution License 4.0 (http://creativecommons.org/licenses/by/4.0/). 
$t_{1}=t_{2}=8 \mathrm{~mm}$, thickness of web $t_{\mathrm{w}}=8 \mathrm{~mm}$, height $h=100 \mathrm{~mm}$, curvature radius $r=2 \mathrm{~m}$, curvature angle $\theta=30^{\circ}$.

In the finite element models, step loads are utilized to make moving loads move from one side of curved box beam to the other side at the speed of $1 \mathrm{~m} / \mathrm{s}$. Constant force, $F=20 \mathrm{~N}$, is chosen to simulate vehicle loads to make shear lag more prominent. The load action mode on the curved box beam is shown as figure1.

In present work, curved box beams are analyzed by the 3D finite element method, using 4-nodes shell elements. The finite element model of curved box beam is shown as figure 2, there are 2204 elements and 2242 nodes, as for boundary conditions, Ux, Uy, Uz and Uy, Uz are restricted at the junction between web and bottom flange in one side, while Ux, Uy and Uy are restricted in the other side.

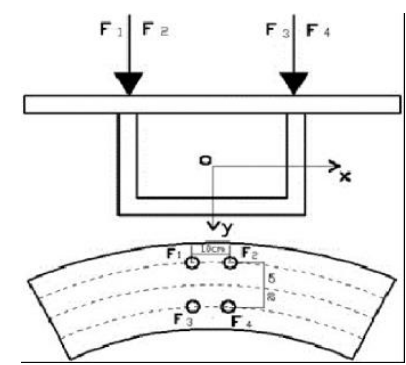

Figure 1. The load action mode on the box beam.

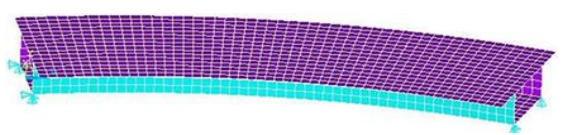

Figure 2. Curved box beam model.

\section{Parametric analysis}

3D finite element analysis is employed so as to reveal shear lag effect under vehicle loads, where 4 parameters, load size, vehicle speed, vehicle load position, load types, are considered . In view of this, the following values are considered: a. $F=20 \mathrm{~N}, 40 \mathrm{~N}, 60 \mathrm{~N}, 80 \mathrm{~N}, 100 \mathrm{~N} ; \mathrm{b} . V=0.1 \mathrm{~m} / \mathrm{s}, 0.3 \mathrm{~m} / \mathrm{s}, 0.5 \mathrm{~m} / \mathrm{s}$, $0.7 \mathrm{~m} / \mathrm{s}, 1 \mathrm{~m} / \mathrm{s}$; c. Move along the mid-line, move along outside, move along inside; $\mathrm{d}$. Constant force, simple harmonic force.

The shear lag effect is most prominent when the loads are applied at the mid-span, the Shear lag coefficient is shown as Eq.(1)[1]

$$
\lambda=\frac{\sigma}{\bar{\sigma}}
$$

Where $\sigma$ is the real stress value, $\bar{\sigma}$ is the stress computed by elementary beam theory.

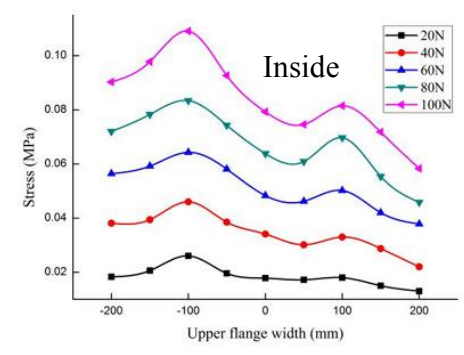

(a) Stress

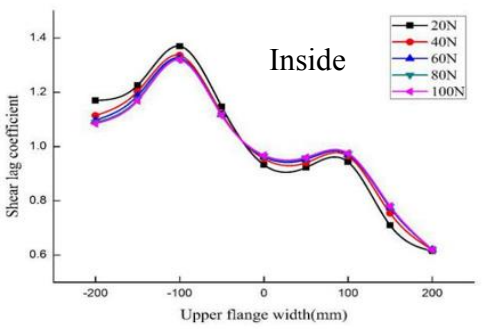

(b) Shear lag coefficient

Figure 3. Shear lag effect under different load size.

In the figure 3, the stress peak is at the junction between upper flange and web, and it gradually decreases along two side, the maximum shear lag coefficient reaches 1.37. However, the stress gets 
larger while shear lag coefficients hardly change with the load size doubles, which indicates that load size have limited influence on shear lag effect.

As is shown in figure 4, the stress become larger with the speed ranging from $0.1 \mathrm{~m} / \mathrm{s}$ to $0.5 \mathrm{~m} / \mathrm{s}$, and then it decreases with the speed ranging from $0.5 \mathrm{~m} / \mathrm{s}$ to $1 \mathrm{~m} / \mathrm{s}$. There is no certain rules for shear lag coefficient with the variation of speed, the shear lag effect is most non-prominent at the speed of $0.7 \mathrm{~m} / \mathrm{s}$.



(a) Stress

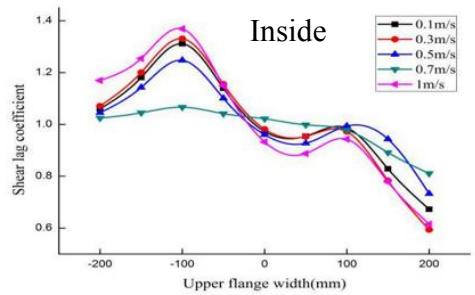

(b) Shear lag coefficient

Figure 4. Shear lag effect under different vehicle speed.

It can be easily found from figure 5 that vehicle load position has a great influence on shear lag effect. Inside shear lag effect is more prominent when the loads move along the inside of upper flange, on the contary, the outside shear lag effect is more prominent, the reason for this is that there is a bigger eccentricity if loads move along mid-line or ouside.

In Fig.6, compared with constant force, although simple harmonic force creates smaller stress on upper flange, but the shear lag coefficients between them are almost the same, which indicates that it is feasible to simplify harmonic force as constant force when shear lag effect of curved box beam under vehicle loads is studied .

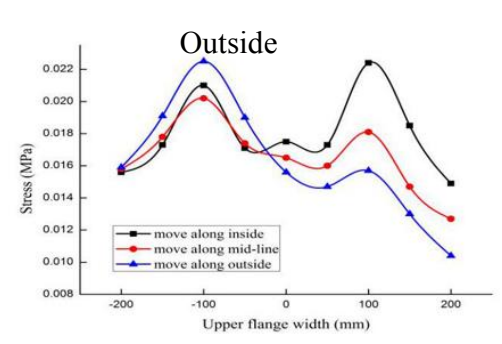

(a) Stress

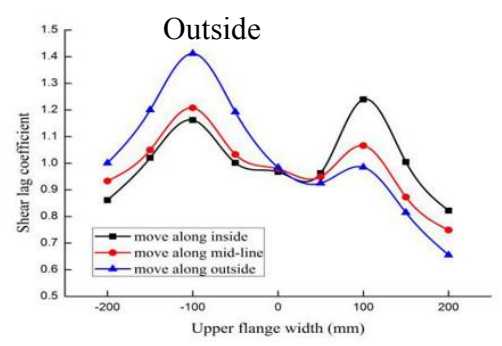

(b) Shear lag coefficient

Figure 5. Shear lag effect under different vehicle load position.

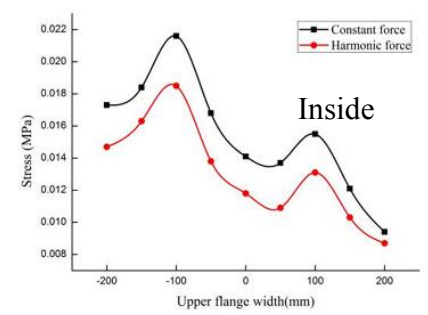

(a) Stress

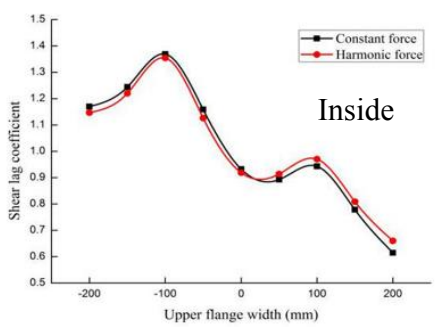

(b) Shear lag coefficient

Figure 6. Shear lag effect under different load types. 


\section{Experimental study}

In present work, model test of cantilever curved box beam is carried out to verify the validity and reliability of finite element model, figure 7 shows the measuring points of upper flange, there are $1 \mathrm{~cm}$ and $L / 2$ from section I and section II to the fixed end respectively, 11 measuring points are laid out on the two sections separately with 5 between two webs and 3 on each cantilever slab.

The results are shown as figure 8, it can be found that the relative error between ANSYS and experiment is small at most of measuring points.



Figure 7. Measuring point of upper flange.



(a) Section I

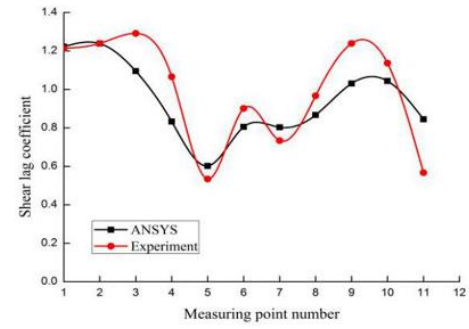

(b) Section II

Figure 8. Shear lag coefficients of section I and section II on upper flange.

\section{Conclusions}

The following conclusions are acquired:

1) The shear lag effect is prominent in the single-box single cell curved box girder at upper flange under vehicle loads.

2) vehicle speed and vehicle load position both have a great influence on shear lag effect, while load size and load types don't affect shear lag coefficient but affect stress.

3) In general, compared with inside shear lag effect, outside shear lag effect is more prominent especially when the loads move along outside, which indicates that the ouside of upper flange is damaged more easily under vehicle loads.

4) the finite element analysis approximately agrees well with experiment results, which verifies the validity and reliability of curved box beam models.

\section{References}

1. H.F. Xiang and L.C. Fan, Advanced Theory of Bridge Structures (China communication Press, Beijing, China 2008)

2. Y.H. Zhang, J Struct Eng-Asce, 138(10), 1279-1284 (2012)

3. W.Q. Wu, S. Wan, J.S. Ye and T.Y. Fang, China Civil Engineering Journal, 37(9), 31-36 (2004)

4. Y.H. Zhang, Y.R. Hu and L.X. Lin, China Civil Engineering Journal, 48(6), 44-50 (2015) 
5. Z.B. Lin and J. Zhao, Eng Struct, 41, 90-97 (2012)

6. W.B. Zhou, L.Z. Jiang, Z.J. Liu and X.J. Liu, J Cent South Univ, 9, 2650-2655 (2012)

7. H.L. Lu, Theoretical Analysis And Experimental Study on Shear-Lag Effect of Prestress Concrete Curved Box Beam (Tianjin University, Tianjin, China, 2007) 